\title{
Neural crest stem cells increase beta cell proliferation and improve islet function in co-transplanted murine pancreatic islets
}

\author{
J. Olerud $\cdot$ N. Kanaykina $\cdot$ S. Vasilovska $\cdot$ D. King $\cdot$ \\ M. Sandberg • L. Jansson • E. N. Kozlova
}

Received: 29 July 2009 /Accepted: 26 August 2009 /Published online: 13 October 2009

(C) Springer-Verlag 2009

\begin{abstract}
Aims/hypothesis Long-term graft survival after islet transplantation to patients with type 1 diabetes is insufficient, necessitating the development of new strategies to enhance transplant viability. Here we investigated whether cotransplantation of neural crest stem cells (NCSCs) with islets improves islet survival and function in normoglycaemic and diabetic mice.

Methods Islets alone or together with NCSCs were transplanted under the kidney capsule to normoglycaemic or alloxan-induced diabetic mice. Grafts were analysed for size, proliferation, apoptosis and insulin release. In diabetic recipients blood glucose levels were examined before and after graft removal.

Results In mixed transplants NCSCs actively migrated and extensively associated with co-transplanted pancreatic islets. Proliferation of beta cells was markedly increased and transplants displayed improved insulin release in normoglycaemic mice compared with those receiving islet-alone transplants. Mixed grafts survived successfully and partially restored normoglycaemia in alloxan-induced diabetic mice. Conclusions/interpretation Co-grafting of NCSCs with pancreatic islets improved insulin release in mixed transplants and enhanced beta cell proliferation, resulting in increased beta cell mass. This co-transplantation model
\end{abstract}

J. Olerud and N. Kanaykina contributed equally to this work.

J. Olerud $\cdot$ M. Sandberg $\cdot$ L. Jansson

Department of Medical Cell Biology,

Uppsala University Biomedical Center,

Uppsala, Sweden

N. Kanaykina $\cdot$ S. Vasilovska $\cdot$ D. King $\cdot$ E. N. Kozlova $(\bowtie)$

Department of Neuroscience, Biomedical Center,

PO Box 593, 75124 Uppsala, Sweden

e-mail: Elena.Kozlova@anatomi.uu.se offers an opportunity to restore neural-islet interactions and improve islet functions after transplantation.

Keywords Diabetes · Islets of Langerhans ·

Neural stem cells · Transplantation - Trophic factor

$\begin{array}{ll}\text { Abbreviations } \\ \text { AMCA } & \text { Aminomethylcoumarin acetate } \\ \text { bTUB } & \text { Beta tubulin class III } \\ \text { EGFP } & \text { Enhanced green fluorescent protein } \\ \text { GFAP } & \text { Glial fibrillary acidic protein } \\ \text { HBSS } & \text { Hanks' balanced salt solution } \\ \text { NCSC } & \text { Neural crest stem cell }\end{array}$

\section{Introduction}

Transplantation of whole pancreas or isolated islets has become a treatment of choice for selected patients with type 1 diabetes mellitus [1,2]. So far, long-term results after islet transplantation are disappointing, with adequate graft function seen in less than $10 \%$ of patients after 5 years [3]. The reasons for graft failure are likely to be multifactorial and include immediate post-transplantation cell death due to hypoxia, leading to a decrease in the number of engrafted beta cells [4]. To increase beta cell mass and restore innervation of transplanted islets are the ultimate goals for successful islet transplantation.

Several growth factors can affect beta cell replication in vitro, whereas expansion of islet endocrine cell mass in vivo is more difficult to achieve [5-7]. Previous experiments have demonstrated that beta cell mass can be expanded during certain conditions with increased demand on function, but the exact mechanisms are as yet unclear $[6,8]$. Several 
studies also suggest that neurotrophins may affect the growth of nerves and beta cells [9, 10].

Recent studies have demonstrated that neural crest stem cells (NCSCs) have an important role in beta cell differentiation by regulating beta cell mass during development [11]. We previously showed that embryonic dorsal root ganglia affect insulin secretion in co-cultured islets [12]. In view of these findings, we investigated here whether co-transplantation of islets and neurospheres derived from NCSC is beneficial for survival, growth and function of transplanted beta cells.

\section{Methods}

Animals Transgenic heterozygous C57BL/6- $\beta$-actin enhanced green fluorescent protein (EGFP) and C57BL/6 mice (Taconic M\&B, Ry, Denmark) were used to generate NCSC neurospheres and for collection of islets. Male C57BL/6 nu/nu mice (Taconic) were used as normoglycaemic or alloxaninduced diabetic graft recipients. In the latter case an intravenous injection of alloxan $(75 \mathrm{mg} / \mathrm{kg}$; Sigma-Aldrich, Irvine, UK) was given and mice with non-fasting blood glucose concentrations above $16.7 \mathrm{mmol} / 15$ days later were considered to be diabetic. All procedures were approved by the Regional Ethics Committee for Research on Animals.

Preparation of NCSC neurospheres Dorsal root ganglia from 11.5 day old EGFP or C57BL/6 mouse embryos were isolated and used to generate NCSC neurospheres from the so-called boundary cap [13]. Briefly, the uterus was removed from the anaesthetised pregnant mouse and placed in cold PBS. Embryos were separated and rinsed in PBS, placed in N2 medium (Invitrogen, Carlsbad, CA, USA), after which the dorsal root ganglia were removed and collected in N2 medium. Collected dorsal root ganglia were allowed to settle before removing the supernatant fractions and adding a collagenase/dispase (1 mg/ml) (Roche Diagnostics Scandinavia, Bromma, Sweden) and DNase solution $(0.5 \mathrm{mg} / \mathrm{ml})$ (Sigma-Aldrich) in N2 medium and incubating for 20 to $30 \mathrm{~min}$ in a $37^{\circ} \mathrm{C}$ water bath. This was followed by rinsing in N2 medium supplemented with B27 (1:50) (Invitrogen) and plating of $\sim 1$ to $2 \times 10^{5}$ cells/well in a 24-well dish after dissociation. Cells were placed directly into $500 \mu 1 \mathrm{~N} 2$ medium containing B27, epidermal growth factor $(20 \mathrm{ng} / \mathrm{ml})$ (R\&D Systems, Minneapolis MN, USA) and basic fibroblast growth factor $(20 \mathrm{ng} / \mathrm{ml})$ (R\&D Systems). After $12 \mathrm{~h}$, non-adherent cells were removed together with half of the medium before adding $250 \mu \mathrm{l}$ of fresh medium. The medium was then changed every other day $(50 \%$ of the medium replaced with fresh medium) before neurospheres began to form. Neurospheres from passages 4 to 5 were used for transplantation experiments.
Islet isolation Pancreatic islets were isolated from C57BL/6 mice by a collagenase digestion method. Briefly, the pancreas was cut into pieces and digested with collagenase (1 $\mathrm{mg} / \mathrm{ml}$; collagenase from Clostridium histolyticum type V; Sigma-Aldrich) for 23 min while being vigorously shaken in a water bath $\left(37^{\circ} \mathrm{C}\right)$. The digestion was terminated with ice-cold Hanks' balanced salt solution (HBSS; The National Bacteriological Laboratory, Stockholm, Sweden). The digest was then sedimented and washed two times in HBSS before islets were handpicked with braking pipettes under a stereo microscope. The islets were cultured free-floating for 3 to 5 days, with 150 islets in each culture dish. Culture medium was $5 \mathrm{ml}$ RPMI 1640 (Sigma-Aldrich) supplemented with L-glutamine (2 mmol/1; Sigma-Aldrich), benzylpenicillin (100 U/ml; Roche), streptomycin (0.1 mg/ml; Roche) and $10 \%$ (vol./vol.) fetal calf serum (Sigma-Aldrich) in 95\% air/ $5 \% \mathrm{CO}_{2}$ at $37^{\circ} \mathrm{C}$ before transplantation or in vitro experiments began. The medium was changed every second day.

Transplantation procedures Normoglycaemic $(n=20)$ or alloxan-induced diabetic $(n=11)$ male C57BL/6 nu/nu mice were anaesthetised with an intraperitoneal injection of avertin $(0.02 \mathrm{ml} / \mathrm{g}$ of body weight of a $2.5 \%$ [vol./vol.] solution of $10 \mathrm{~g} \mathrm{97 \%} \mathrm{2,2,2-tribromo-ethanol} \mathrm{[Sigma-Aldrich]} \mathrm{in}$ $10 \mathrm{ml}$ 2-methyl-2-butanol [Kemila, Stockholm, Sweden]) and the kidney(s) were exposed through a flank incision. Normoglycaemic mice received 150 islets under the capsule of the right kidney and 75 islets +75 neurospheres mixed together into one graft under the capsule of the left kidney. Alloxan-induced diabetic mice received a graft of 300 islets $(n=6)$ (the number of islets was chosen on the basis of our previous studies in this strain [14] and aimed to provide sufficient islet mass for full reversal of hyperglycaemia in all control diabetic recipients) or a mixed graft of 150 islets and 150 neurospheres $(n=5)$.

Monitoring of alloxan-injected mice The body weight and blood glucose concentration of the alloxan-injected transplanted animals were measured every fifth day during the 1 month follow-up. Cure from diabetes was defined as nonfasting blood glucose concentrations $\leq 11.1 \mathrm{mmol} / 1$.

One month after transplantation the alloxan-induced diabetic mice were subjected to an intravenous glucose tolerance test ( $n=11$, of which five had had 150 islets +150 neurospheres transplanted and six had had 300 islets transplanted). Several alloxan-injected mice died $(n=1$ with islet-alone transplant, $n=2$ with mixed transplant). Mice were injected intravenously with $3 \mathrm{~g} / \mathrm{kg}$ body weight D-glucose (glucose $300 \mathrm{mg} / \mathrm{ml}$; Fresenius Kabi, Uppsala, Sweden) into the tail vein. Glucose measurements were made on blood from the cut tip of the tail with glucose reagent strips (MediSense, Solna, Sweden) before glucose 
injection and at 10,16, 30, 60 and 120 min later. On the day after the glucose tolerance test the graft-bearing kidney was removed and blood glucose concentrations were measured 2 to 5 days later.

Morphological evaluation of grafts to normoglycaemic mice We collected transplants at 2 days and at 1 month after transplantation to normoglycaemic mice. On the 2nd day after implantation the graft-bearing kidney was removed and fixed in 10\% (vol./vol.) formalin overnight, followed by rinsing in water, dehydration and embedding in paraffin. Specimens were cut serially at $5 \mu \mathrm{m}$ and parallel sections were labelled with insulin antibodies (guinea pig polyclonal, 1:250; Fitzgerald Industries, Concord, MA, USA) and for the proliferation-associated protein Ki67 (mouse, monoclonal 1:200; Dako, Glostrup, Denmark) or for apoptotic cells with TUNEL staining ( $n=7$ and $n=5$, respectively) and counterstained with haematoxylin. Counts of Ki67- and TUNEL-labelled cells were made in endocrine areas of islet-alone and mixed grafts. TUNEL-positive cells were assessed in 1,000 randomly placed frames (side $0.11 \mathrm{~mm}$ ) through the endocrine part of the entire grafts ( $n=5$ for islet transplants, $n=5$ for mixed grafts). Ki67positive cells were assessed in 400 randomly placed frames through the endocrine part of the entire grafts ( $n=7$ for islet transplants, $n=7$ for mixed grafts).

Serial sections from 1-month-old transplants $(n=7)$ were stained with a monoclonal guinea pig anti-insulin antibody (Fitzgerald Industries) and the immune complex visualised with horseradish peroxidase-conjugated secondary antibodies (Dako), using diaminobenzidine as substrate. Estimates of the entire islet-alone and mixed transplant volume, as well as of the volume of the beta cell compartments were calculated. Every fifth section, stained with anti-insulin antibodies and prepared from the grafts $(n=4$ in each group) from 2-day-old and 28-day-old transplants, was photographed, and transplant areas and beta cell areas were measured with National Institutes of Health (NIH) software (ImageJ, available at http://rsb.info.nih.gov/ij). Estimates of the entire transplant volume as well as of the volume of the beta cell compartment in the transplant were calculated according to the formula $A=T K\left[\sum\left(S_{1}\right.\right.$ to $\left.\left.S_{n}\right)\right]$, where $T$ is the thickness of the section $(T=12 \mu \mathrm{m}), K$ is the number of sections between the measured areas $(K=5)$ and $S$ is the area of the transplant on the sections from 1 to $n$.

Perifusion of grafts Normoglycaemic mice $(n=6)$ used for these studies were anaesthetised with avertin (see above) at 1 month after transplantation. Grafts were identified and a small incision was made in the renal capsule immediately adjacent to each of the grafts. By carefully lifting the capsule, this could be removed together with the grafts. The transplants were then perifused to assess their insulin secretion in response to glucose stimulation [15]. Briefly, islet grafts consisting of 150 islets or 75 islet +75 neurosphere grafts were placed in small chambers $\left(\sim 1 \mathrm{~mm}^{3}\right)$ with a bottom consisting of a polyamide net (mesh size $25 \mu \mathrm{m}$ ) and perifused with $1 \mathrm{ml} / \mathrm{min}$ of $\mathrm{KRBH}$ with the addition of $1 \% \mathrm{BSA}(\mathrm{wt} / \mathrm{vol}$.) and $2.8 \mathrm{mmol} / 1 \mathrm{D}$-glucose for $30 \mathrm{~min}$. After this normalisation period, a solution of $\mathrm{KRBH}+1 \%$ BSA with $28 \mathrm{mmol} / 1 \mathrm{D}$-glucose was perifused for $30 \mathrm{~min}$, followed by $\mathrm{KRBH}+\mathrm{BSA}$ with $2.8 \mathrm{mmol} / \mathrm{l} \mathrm{D}$-glucose for $20 \mathrm{~min}$. Samples were taken for analysis of insulin at every min from $20 \mathrm{~min}$ and onwards. Insulin was analysed with rat insulin ELISA (Mercodia, Uppsala, Sweden).

Immunofluorescence Double or triple immunofluorescence labelling was performed on mixed grafts and islet-alone grafts 2 days and 1 month after transplantation $(n=3$ for each group). Transplants were fixed for $2 \mathrm{~h}$ in $4 \%$ formaldehyde (vol./vol.) and $14 \%$ saturated picric acid (wt/vol.) in PBS (ca. $4^{\circ} \mathrm{C} ; \mathrm{pH} 7.4$ ), left over night in PBS containing $15 \%$ sucrose, cut on cryostat into $12-\mu \mathrm{m}$ thick sections and labelled with primary antibodies for insulin (see above) to visualise beta cells. They were also labelled with beta tubulin class III (bTUB) (mouse monoclonal, 1:500; Covance, Princeton, NJ, USA) and anti-glial fibrillary acidic protein (GFAP) (rabbit polyclonal, 1:400; Dako) to identify transplanted NCSCs that had differentiated to neurones and glia respectively, and with Ki67 (see above). After washing with PBS, the following secondary antibodies (Jackson ImmunoResearch, Newmarket, UK) were applied for $4 \mathrm{~h}$ at room temperature: (1) Cy3-conjugated donkey anti-mouse (1:500); (2) Cy2, aminomethylcoumarin acetate (AMCA) or Cy3-conjugated anti-guinea pig (1:500); and (3) AMCAconjugated donkey anti-rabbit (1:100). Sections were rinsed three times in PBS for $15 \mathrm{~min}$ (the second wash in some sections included Hoechst 33342, 11 ng/ml; Molecular Probes, Burlingame, CA, USA) and mounted in a mixture of PBS and glycerol (1:1; vol./vol.) containing $0.1 \mathrm{~mol} / 1$ propylgallate (Molecular Probes).

Statistical analysis Values given are means \pm SEM. Probabilities $(p)$ of chance differences were calculated with Student's unpaired $t$ test or Wilcoxon's rank-sum-test. $p$ values of $<0.05$ were considered to be statistically significant. For multiple comparisons between data ANOVA and Bonferroni post-hoc test were used.

\section{Results}

Survival and function of beta cells transplanted to the kidney The transplants were easily identified in the kidneys of the recipient animals both at 2 days and 1 month after transplantation. Islet-alone grafts were identified at the place 
of the grafting, whereas in the kidney containing a mixture of islets and NCSCs, the grafts often occupied a larger area under the kidney capsule and looked flatter than islet-alone transplants. The morphology of the islet grafts at 2 days after transplantation demonstrated a compact mass of endocrine cells (Fig. 1a), sometimes with a central core of loose connective tissue, whereas mixed grafts often contained a single fluid-filled cyst in the central portion of the grafts (Fig. 1b).

Morphology of transplants The interrelations between beta cells and NCSCs in mixed grafts developed early after transplantation. Already at 2 days the NCSCs were located at the periphery of the tightly packed insulin-positive areas and were extensively dispersed in different directions from the site of transplantation under the kidney capsule. In some cases, the NCSCs attached to insulin-positive cells (Fig. 1c) or were in close proximity to islet cells (Fig. 1d). At this stage the NCSCs extensively expressed GFAP and showed almost complete overlap with EGFP natural staining (not shown). We also registered GFAP-positive extensions from the NCSCs to some parts of the insulin-positive areas (Fig. 1h). In case of cyst formation, the NCSCs covered the
Fig. 1 Transplants at 2 days post-transplantation. a Isletalone transplant is in close apposition to the kidney, whereas mixed transplant (b) displays a cyst in the middle (sections labelled for insulin and counterstained with haematoxylin). c Mixed graft in which some insulin-producing cells (blue) are completely covered by EGFP-expressing NCSCs (green), whereas in other parts of the transplant (d) NCSCs (blue) are located in the immediate vicinity of the tightly packed insulin-positive cells (green). e Ki67-labelled endocrine cells (dark-brown) in islet-alone and (f) in mixed transplants. g Triple labelling of islet-alone and (h) a mixed graft: insulin-positive cells (green) are located on the top of the graft co-expressing Ki67 (red), with an occasional GFAP-expressing cell (blue) in the vicinity of the graft (h). Scale bars, $300 \mu \mathrm{m}$ (a, b), $200 \mu \mathrm{m}$ (d), $100 \mu \mathrm{m}$ (c) and $20 \mu \mathrm{m}(\mathbf{e}-\mathbf{h})$. j Graph showing the fraction of Ki67labelled cells in endocrine areas of the islet-alone and mixed grafts $(n=7 ; p<0.001$

Wilcoxon's rank-sum test)
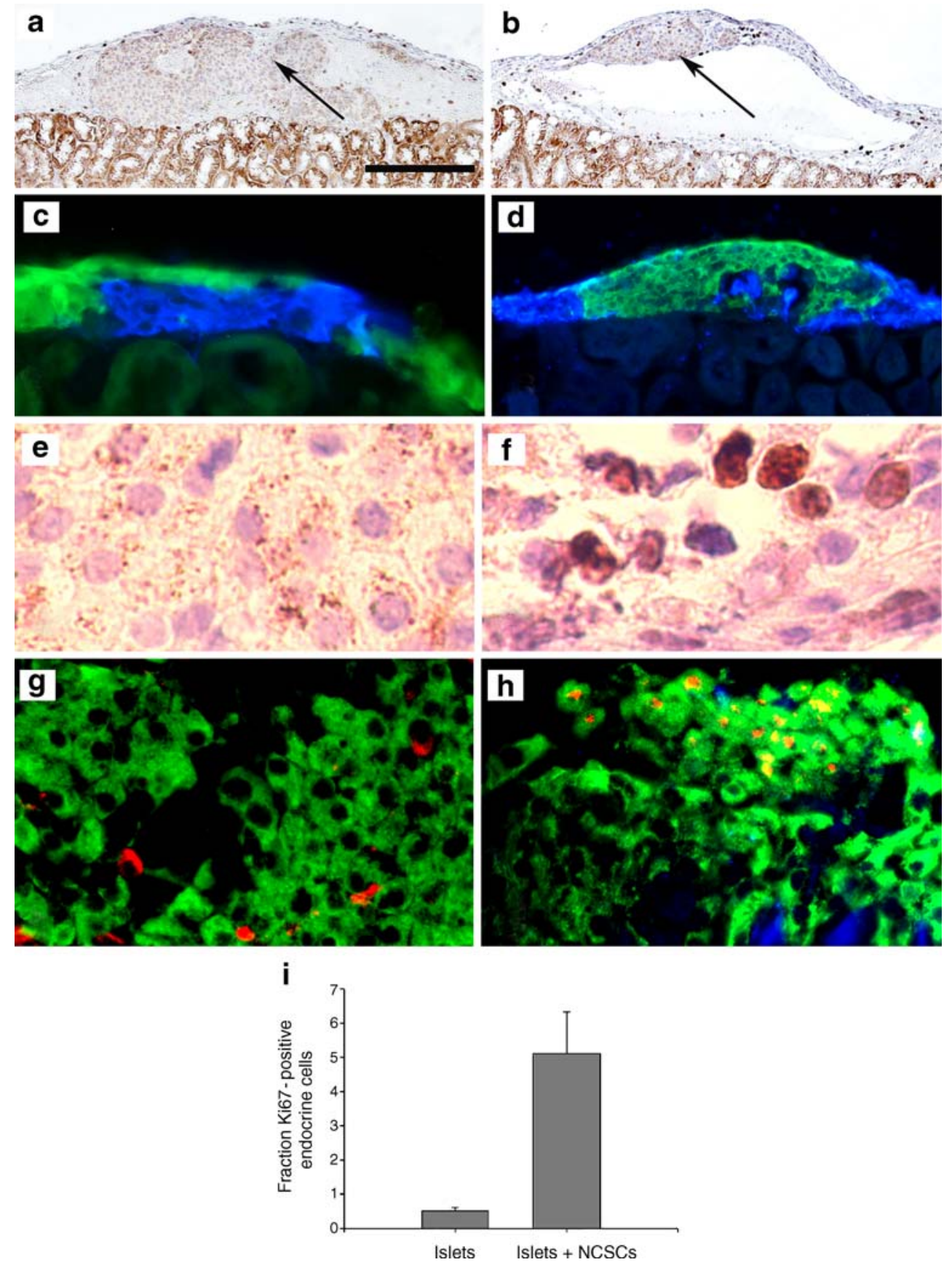
entire inner surface of the cysts, thus isolating the islet cells from the fluid.

Immunostaining of 2-day-old transplants TUNEL or Ki67 staining was made on adjacent insulin-labelled sections. No difference in the incidence of TUNEL-positive cells was seen in islet-alone compared with mixed grafts $(0.19 \pm 0.03$ vs $0.21 \pm 0.04 \%$ of the endocrine cells, respectively) (not shown). In contrast, the number of Ki67-positive endocrine cells within mixed grafts was strongly increased (Fig. 1e, f) and ten times higher than in islet-alone transplants (Fig. 1i). To determine whether beta cells contributed to the proliferation in the endocrine areas of mixed transplants, we performed triple immunofluorescence labelling with antibodies to insulin, the proliferation marker Ki67 and GFAP. Our findings showed that insulinpositive cells extensively contributed to the population of proliferating cells in the endocrine areas of mixed transplants, whereas only occasional dividing insulin-negative cells were found in islet-alone transplants (Fig. 1g, h). The insulin- positive proliferating cells in mixed transplants were located in clusters and cells were smaller than insulin-positive cells in neighbouring areas or in islet-alone transplants (Fig. 1h). At this stage the insulin-positive cell volume in mixed grafts was smaller than that of islet-alone grafts in line with the smaller number of transplanted islets in the mixed grafts (Fig. 2f).

Immunostaining of 1-month-old transplants At 1 month after transplantation large areas in islet-alone as well as in mixed transplants were occupied by insulin-positive or by insulin-negative endocrine cells (Fig. 2a, b). The NCSCs were found in direct vicinity of the insulin-positive cells (Fig. 2c-e) and extensively expressed the glial marker GFAP or the neuronal marker bTUB. The proportion of insulin-positive cells of the entire graft size constituted $31 \pm 6 \%$ of islet-alone $(n=6)$ and $12 \pm 3 \%$ of mixed $(n=7)$ grafts $(p<0.027$, Wilcoxon's rank-sum test). However, the beta cell volume within the grafts was similar in islet-alone and in mixed grafts $(p=0.42)$ (Fig. 2f). The beta cell volume in mixed 1-month-
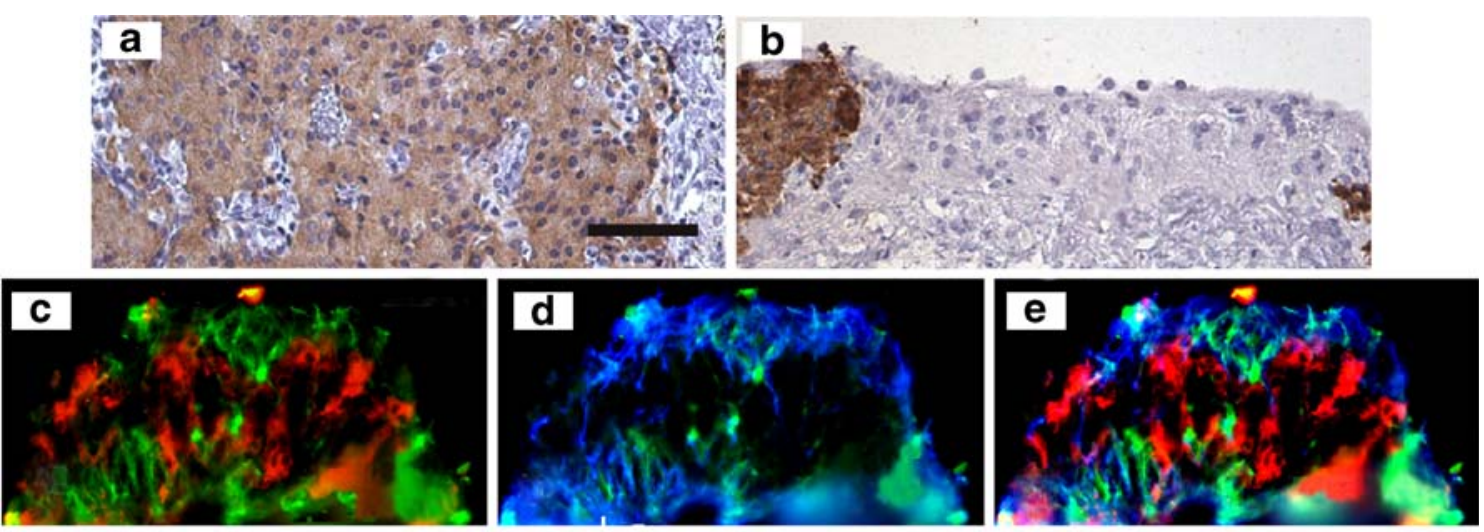

f
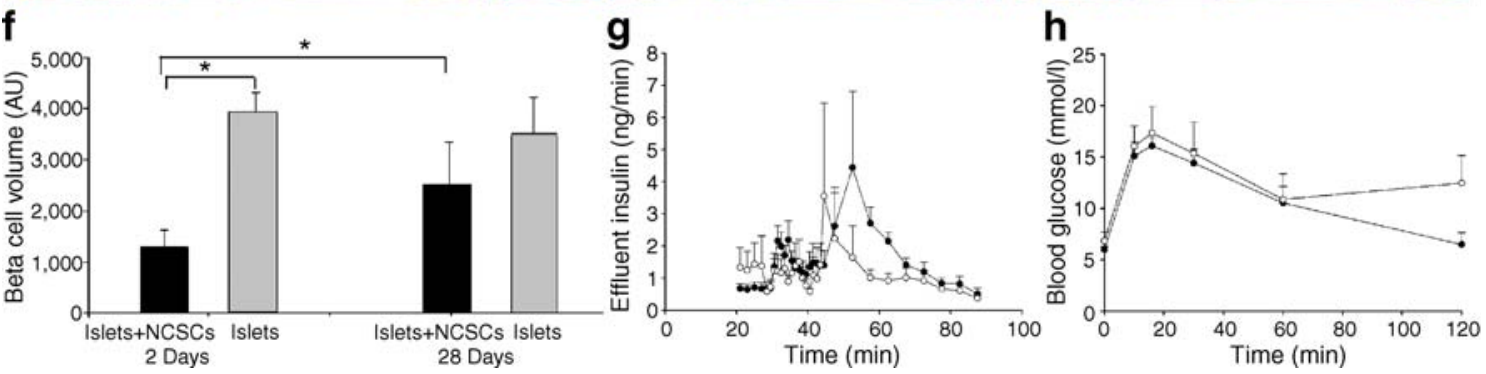

Fig. 2 Transplants at 1 month post-transplantation. a Transplants consisting of islets alone with a high proportion of insulin-positive cells or (b) of a mixture of islets and NCSCs. Sections are immunolabelled for insulin (brown). c-e Mixed islet-NCSC grafts. EGFP-expressing NCSCs (green) surround groups of islet cells (red), but distinct boundaries between the two cell types are still maintained. NCSCs predominantly differentiate to glial cells as shown by double labelling of EGFP (green) and anti-GFAP (blue). Scale bar, $100 \mu \mathrm{m}$ (a, b), $50 \mu \mathrm{m}$ (c-e). f Volume of beta cell population within islets-alone transplants (Islets) or mixed islet-NCSC transplants (Islets+NCSCs) at 2 days and at 1 month after transplantation. Islet grafts consisted of 150 islets, mixed grafts of 75 islets +75 neurospheres. Values are means \pm SEM for six to seven experi- ments. ${ }^{*} p \leq 0.05$ for Islets + NCSCs grafts at 2 days compared with 28 days and for Islets + NCSCs and islets alone at 2 days. g Grafts containing 150 islets (black circles) and 75 islets +75 neurospheres (white circles) were perifused $(1 \mathrm{ml} / \mathrm{min}$ ) in small chambers and insulin quantified. Values are means \pm SEM for six to seven experiments. All values between 30 and 60 min were higher $(p<0.05)$ than the values at time $30 \mathrm{~min}$ in both groups (Student's unpaired $t$ test; significances not given in figure). $\mathbf{h}$ Intravenous glucose tolerance tests in alloxaninduced diabetic mice at 1 month after grafting of 300 islets alone (black circles) or 150 islets +150 neurospheres (white circles). Both groups of animals show normal glucose tolerance at the different time points tested 
old transplants was significantly increased compared with that in 2-day-old transplants ( $p=0.037$ ) (Fig. 2f).

Functional evaluation of transplants Stimulation of the grafts with a high glucose concentration in perifusion experiments induced a biphasic release of insulin from islet-alone and mixed grafts, with no differences in the total amount of insulin released from the grafts as evidenced by similar values for area under the curve when insulin release was plotted against time (Fig. 2g). However, initiation of insulin release was significantly faster in mixed transplants (Fig. 2g).

Alloxan-induced diabetic mice treated with a graft of 300 islets showed a normoglycaemic response in the glucose tolerance test at 1 month after grafting. Alloxaninduced recipients receiving mixed grafts (150 islets and 150 neurospheres) showed a similar response, although blood glucose values tended to be higher at $120 \mathrm{~min}$ (difference not significant, $p=0.074$ ) (Fig. 2h).

In seven alloxan-induced diabetes graft recipients that had been cured by an islet-alone or mixed graft, the transplants ( $n=3$ and $n=4$ respectively) were removed and diabetes developed again as confirmed by blood tests showing glucose levels above $11.1 \mathrm{mmol} / 1$ after nephrectomy.

\section{Discussion}

The ultimate goal of the present work is to develop a new method for islet transplantation, which will allow grafted pancreatic islets to receive neurotrophic support and reinnervation in order to improve their long-term survival and function. We previously showed that after 1 month NCSCs migrate towards islets when transplanted to different poles of the same kidney [16].

In this co-transplantation study, we demonstrate that NCSCs develop interconnections with islet cells from the first days after transplantation. These early interactions between co-grafted NCSCs and islets promote proliferation of beta cells in the transplant and subsequently resulted in an increased beta cell mass. Furthermore, we show that mixed grafts successfully survive transplantation in alloxaninduced diabetic mice and in normoglycaemic recipients.

The endocrine pancreas normally possesses a rich innervation consisting of many types of neurones, which help to modulate endocrine secretion [17, 18]. After implantation under the kidney capsule, the entire extrinsic innervation to the implanted islets is lost and is only slowly replaced by nerves growing in from surrounding structures, mainly in association with blood vessels [19, 20]. Furthermore, neurones present in islet grafts do not seem to survive for more than up to 1 week after transplantation [21]. Immunohistochemical analysis of mixed transplants revealed the presence of neurones and glial cells originating from the transplanted NCSCs at 2 days and at 1 month after transplantation. Although islets and NCSCs seemed to remain separate, we noted penetration of fibres from NCSCs into the islet compartment. We found no labelling with antibodies that identify specific sensory neurone subtypes (S. Vasilovska and E. N. Kozlova, unpublished observations), indicating that specific stimulation of neuronal differentiation may be necessary to achieve reinnervation of islets from co-transplanted NCSCs. We recently demonstrated that subtype-specific differentiation of NCSCs after transplantation of only neurospheres can be induced by activating specific transcription factors [22]. This approach provides an opportunity to re-innervate islets from differentiated NCSCs in this transplantation setting.

In 2-day-old transplants we found a markedly increased cell proliferation in endocrine areas of mixed compared with islet-alone grafts, whereas the level of apoptosis was the same in both types of graft. Double labelling with Ki67 and insulin revealed that specifically beta cells proliferated extensively. This high rate of endocrine cell proliferation in combination with similar levels of apoptosis in early mixed compared with islet-alone transplants appeared to have significant consequence for growth of the islets in mixed grafts. Thus, at 2 days the beta cell volume in the mixed grafts was smaller than that of islet-alone grafts, consistent with the fact that only half the number of islets was implanted in the mixed grafts. However, at 1 month post-transplantation, the insulin-positive cell volume was similar in mixed and islet-alone grafts. These data indicate that NCSCs contributed to increased beta cell mass in mixed transplants. Further studies are necessary to determine whether this effect is mediated directly by the cografted NCSCs or indirectly, e.g. through stimulation of blood vessel growth into the transplant.

NCSCs play an important role in regulating beta cell mass during embryonic development. In a mouse knockout model in which islet innervation fails to develop, beta cell replication is enhanced and beta cell mass increased, indicating that neural cells inhibit beta cell proliferation in the developing pancreas [11]. Our results, however, show that NCSCs potently stimulate beta cell proliferation in cotransplanted islets. In fact, the rate of proliferation in our experiments was much higher than has been reported in previous studies on induced beta cell replication [23]. These seemingly contradictory findings may reflect differences in the origin of newly formed beta cells in developing and adult islets. In development, endodermal progenitor cells are the source of beta cells, whereas renewal of such cells in adult islets can occur from differentiated beta cells [24, 25]. Thus, in our experiments using adult islets, co-transplanted NCSCs may have prevented proliferation of beta cell precursors, but at the same time stimulated proliferation of differentiated beta cells. Our pilot in vitro experiments confirm this hypothesis (unpublished observations). 
An intriguing finding in 2-day-old mixed transplants was the presence of a single fluid-filled cyst. We did not see similar cysts in this or in our previous studies with isletalone or NCSC-alone transplants [12]. These cysts presumably arose as a result of the presence of undifferentiated NCSCs or from NCSC-islet-duct cell interactions during the early post-grafting stage. Analysing the content of the fluid in these cysts may help to identify factors produced by mixed grafts that enhance islet cell proliferation. We are currently developing a method for such analyses.

At 1 month post-transplantation, the beta cell volume was similar in mixed and islet-alone grafts, despite the fact that only half as many islets were implanted in mixed grafts. Growth factors released from co-grafted NCSCs may have been instrumental in the initiation of endocrine cell proliferation and in maintaining newly formed beta cells. Several studies have suggested that growth factors released from neural cells, such as nerve growth factor, brainderived neurotrophic factor, ciliary neurotrophic factor and glial cell line-derived neurotrophic factor, may affect the growth or maintenance of nerves and beta cells [9, 26-28]. Furthermore, islet injury can increase sensitivity to neurotrophins [10], while an improvement in islet survival after transplantation was seen in rodents following treatment with nerve growth factor [9].

Our study demonstrates in perifusion experiments that 1-month-old mixed grafts performed equally well as isletalone grafts, even though the latter contained twice as many islets at the time of transplantation. We also noted a faster insulin release from mixed transplants, which may reflect a difference in the vascular anatomy and/or revascularisation of the combined grafts, speeding access of the perifusion medium to the beta cells. Alternatively, stimulation from NCSCs may result in an earlier functional maturation or facilitated release of secretory granules in beta cells of mixed transplants. These findings indicate that in addition to a growth- and survival-promoting effect, NCSCs also exert positive effects on the function of cografted beta cells.

To probe the potential of NCSC-islet grafts to cure diabetes, we implanted in alloxan-induced diabetic mice a mixed graft containing, in addition to 150 NCSCs, only 150 islets. In comparison with our previous data showing that 200 islets are insufficient to cure alloxan-induced diabetic mice [14], these data show that in mixed transplants containing only 150 neurospheres we had partial improvement of endocrine function. Indeed, the measurements at early time points were similar between animals receiving islets alone and those receiving mixed transplants. However, at 120 min there was a slight difference in values. Thus our experiments clearly demonstrate that mixed grafts, when challenged by a diabetic environment, were able to survive and attenuate the diabetes.
In summary, we have demonstrated that NCSCs develop direct contacts with co-transplanted islets and promote both proliferation and growth of beta cells, and that these effects are paralleled by a corresponding functional improvement in normoglycaemic and diabetic mice. These findings provide a basis for further studies on the interaction between neural stem cells and pancreatic islets, with the ultimate goal of developing techniques to achieve a functionally optimal beta cell mass after transplantation.

Acknowledgements This work was supported by the Swedish Research Council (projects 5420 and 20716, and 72X-109 and 62X20716), a grant from Stiftelsen Olle Engkvist Byggare, the Swedish Diabetes Association, the Juvenile Diabetes Research Foundation, the Wallenberg Foundation and the Family Ernfors Fund. N. Kanaykina was supported by the Swedish Institute. The skilled technical assistance of A. Nordin is gratefully acknowledged.

Duality of interest The authors declare that there is no duality of interest associated with the manuscript.

\section{References}

1. Frank AM, Barker CF, Markmann JF (2005) Comparison of whole organ pancreas and isolated islet transplantation for type 1 diabetes. Adv Surg 39:137-163

2. Ryan EA, Bigam D, Shapiro AM (2006) Current indications for pancreas or islet transplant. Diabetes Obes Metab 8:1-7

3. Ryan EA, Paty BW, Senior PA et al (2005) Five-year follow-up after clinical islet transplantation. Diabetes 54:2060-2069

4. Davalli AM, Scaglia L, Zangen DH, Hollister J, Bonner-Weir S, Weir GC (1996) Vulnerability of islets in the immediate posttransplantation period. Dynamic changes in structure and function. Diabetes 45:1161-1167

5. Baggio LL, Drucker DJ (2006) Therapeutic approaches to preserve islet mass in type 2 diabetes. Annu Rev Med 57:265-281

6. Bouwens L, Rooman I (2005) Regulation of pancreatic beta-cell mass. Physiol Rev 8:1255-1270

7. Vasavada RC, Gozalez-Pertusa JA, Fujimaka Y, Fiaschi-Taesch N, Cozar-Castellano I, Garcia-Ocana A (2006) Growth factors and beta cell replication. Int J Biochem Cell Biol 38:931-950

8. Bonner-Weir S (2000) Islet growth and development in the adult. J Molecular Endocrinol 24:297-302

9. Miao G, Mace J, Kirby $M$ et al (2006) In vitro and in vivo improvement of islet survival following treatment with nerve growth factor. Transplantation 81:519-524

10. Teitelman G, Guz Y, Ivkovic S, Ehrlich M (1998) Islet injury induces neurotrophin expression in pancreatic cells and reactive gliosis of peri-islet Schwann cells. J Neurobiol 34:304-318

11. Nekrep N, Wang J, Miyatsuka T, German MS (2008) Signals from the neural crest regulate beta-cell mass in the pancreas. Development 135:2151-2160

12. Kozlova EN, Jansson L (2005) In vitro interactions between insulin-producing beta cells and embryonic dorsal root ganglia. Pancreas 31:380-384

13. Hjerling-Leffler J, Marmigere F, Heglind M et al (2005) The boundary cap: a source of neural crest stem cells that generate multiple sensory neuron subtypes. Development 132:2623-2632

14. Mattsson G, Jansson L, Nordin A, Carlsson PO (2003) Impaired revascularization of transplanted mouse pancreatic islets is chronic and glucose-independent. Transplantation 75:736-739 
15. Tyrberg B, Andersson A, Borg LA (2001) Species differences in susceptibility of transplanted and cultured pancreatic islets to the beta-cell toxin alloxan. Gen Comp Endocrinol 122:238-251

16. Kozlova EN, Jansson L (2009) Differentiation and migration of neural crest stem cells are stimulated by pancreatic islets. Neuroreport 20:833-838

17. Ahrén B (2000) Autonomic regulation of islet hormone secretion -implications for health and disease. Diabetologia 43:393-410

18. Brunicardi FC, Shavelle DM, Andersen DK (1995) Neural regulation of the endocrine pancreas. Int J Pancreatol 18:177-195

19. Korsgren O, Jansson L, Andersson A, Sundler F (1992) Reinnervation of transplanted pancreatic islets: a comparison between islets implanted into the kidney, spleen, or liver. Transplant Proc 24:1025-1026

20. Persson-Sjögren S, Forsgren S, Täljedal IB (2000) Peptides and other neuronal markers in transplanted pancreatic islets. Peptides 21:741-752

21. Persson-Sjögren S, Forsgren S, Rooth P, Täljedal IB (1996) Initial increase and subsequent loss of vasoactive intestinal polypeptide immunoreactivity in acetylcholinesterase-positive neurons of mouse islets transplanted to the kidney. Cell Tissue Res 284:391-400
22. Aldskogius H, Berens C, Kanaykina N et al (2009) Regulation of boundary cap neural crest stem cell differentiation after transplantation. Stem Cells 27:1592-1603

23. Andersson A, Carlsson PO, Carlsson C et al (2004) Promoting islet cell function after transplantation. Cell Biochem Biophys 40 (3 Suppl):55-64

24. Dor Y, Brown J, Martinez OI, Melton DA (2004) Adult pancreatic beta-cells are formed by self-duplication rather than stem-cell differentiation. Nature 429:41-46

25. Teta M, Rankin MM, Long SY, Stein GM, Kushner JA (2007) Growth and regeneration of adult beta cells does not involve specialized progenitors. Dev Cell 12:817-826

26. Yamanaka M, Itakura $Y$, Inoue $T$ et al (2006) Protective effect of brain-derived neurotrophic factor on pancreatic islets in obese diabetic mice. Metabolism 55:1286-1292

27. Rezende LF, Stoppiglia LF, Souza KL, Negro A, Langone F, Boschero AC (2007) Ciliary neurotrophic factor promotes survival of neonatal rat islets via the BCL-2 anti-apoptotic pathway. J Endocrinol 195:157-165

28. Mwangi S, Anitha M, Mallikarjun C et al (2008) Glial cell linederived neurotrophic factor increases beta-cell mass and improves glucose tolerance. Gastroenterology 134:727-737 